\title{
NOTCH3 T6746C and TP53 P72R Polymorphisms Are Associated with the Susceptibility to Diffuse Cutaneous Systemic Sclerosis
}

\author{
Szymon Zmorzyński (iD, ${ }^{1}$ Magdalena Wojcierowska-Litwin, ${ }^{1}$ Małgorzata Kowal, ${ }^{2}$ \\ Małgorzata Michalska-Jakubus, ${ }^{2}$ Wojciech Styk (D), ${ }^{3}$ Agata Anna Filip, ${ }^{1}$ Irena Walecka, ${ }^{4}$ \\ and Dorota Krasowska ${ }^{2}$ \\ ${ }^{1}$ Department of Cancer Genetics with Cytogenetic Laboratory, Medical University of Lublin, Lublin, Poland \\ ${ }^{2}$ Chair and Department of Dermatology, Venerology and Pediatric Dermatology, Medical University of Lublin, Lublin, Poland \\ ${ }^{3}$ Institute of Psychology, The John Paul II Catholic University of Lublin, Lublin, Poland \\ ${ }^{4}$ Department of Dermatology, Centre of Postgraduate Medical Education, Warsaw, Poland
}

Correspondence should be addressed to Szymon Zmorzyński; s.zmorzynski@gmail.com

Received 18 September 2019; Revised 15 December 2019; Accepted 21 January 2020; Published 25 February 2020

Academic Editor: Francesco Del Galdo

Copyright (c) 2020 Szymon Zmorzyński et al. This is an open access article distributed under the Creative Commons Attribution License, which permits unrestricted use, distribution, and reproduction in any medium, provided the original work is properly cited.

Introduction. NOTCH pathway and TP53 protein are involved in the development of fibrosis and autoimmune disorders, respectively. The aim of this study was to evaluate the role of single nucleotide polymorphisms (SNPs) of NOTCH3 and TP53 genes and serum anti-TP53 antibodies with the susceptibility, clinical subset of systemic sclerosis (SSc), and clinical profile of SSc patient, particularly with lung involvement and disease activity. Objects and Methods. 124 white Polish SSc patients (101 with limited cutaneous SSc-lcSSc, and 23 with diffuse cutaneous SSc-dcSSc) and 100 healthy individuals were included in the study. Patients were assessed for the presence of autoantibodies and interstitial lung disease. Two SNPs at position 6746 of NOTCH3 gene (C/T alleles) and 215 of the TP53 gene (P/R alleles) were genotyped by PCR-restriction fragment length polymorphism. Serum levels of anti-TP53 antibodies were analyzed by means of ELISA. Results. The genotypic frequencies of the NOTCH3 gene for SSc patients diverged significantly from Hardy-Weinberg equilibrium $\left(p=0.03 ; \chi^{2}=4.63\right)$. There was no significant difference between SSc patients and the control population in allele frequencies of both SNPs. The CT + CC genotypes of NOTCH3 influenced the susceptibility to SSc $(\mathrm{OR}=1.85, p=0.04)$, including dcSSc $(\mathrm{OR}=3.43, p=0.04)$, and active form of SSc $(\mathrm{OR}=5.46, p<0.001)$. The PR $+\mathrm{RR}$ genotypes of the TP53 gene were associated only with dcSSc susceptibility $(\mathrm{OR}=3.30$, $p=0.034)$. The levels of anti-TP53 antibodies were not related to studied SNPs and clinical parameters of SSc including the presence of specific antibodies and interstitial lung disease. Conclusion. The CT + CC genotypes of NOTCH3 gene and PR + RR genotypes of the TP53 gene increased the risk of dcSSc development. Moreover, genotypes of CT + CC were associated with the active form of SSc suggesting the role of the NOTCH pathway in the pathogenesis of this disease.

\section{Introduction}

Systemic sclerosis (SSc) is a connective tissue disease characterized by vascular dysfunction, the presence of autoantibodies, and inflammatory-driven fibrosis of the skin and internal organs $[1,2]$. The disease manifests clinically as limited cutaneous SSc (lcSSc) or diffuse cutaneous SSc $(\mathrm{dcSSc})$ distinguished mainly on the pattern of skin involvement: lcSSc form is characterized by skin involvement restricted to hands, face, forearms, and feet, whereas in dcSSc skin sclerosis extends proximal to the elbow and may involve truncal areas [3-5]. Interstitial lung disease is observed in up to $50 \%$ of SSc patients and is featured by activation of the NOTCH pathway involved in the differentiation of myofibroblasts $[6,7]$. These cells are characterized by high proliferative capacity, which produce more extracellular matrix and in many cases do not respond to apoptotic signals [7]. 
NOTCH pathway is a conserved signaling system mediating cell differentiation, proliferation, survival, and apoptosis [8]. The NOTCH3 receptor regulates T-cell differentiation, which may be associated with autoimmunity [9]. NOTCH3 gene (locus 19p13.12) encodes type I transmembrane receptor protein [10]. The role of single nucleotide polymorphisms (SNPs) in the coding sequence of NOTCH3 gene remains unknown. The most common SNP, present in exon 33 (T6746C), causes a substitution of $\mathrm{T}$ ( $\mathrm{T}$ allele) by $\mathrm{C}$ (C allele) (GTG to GCG) and results in the exchange of valine to alanine in protein chain (Val2223Ala). The residue 2223 is located in the intracellular domain, which is thought to play a role in signal transduction associated with lung fibrosis or active SSc [7]. The role of this SNP in SSc was previously not analyzed.

Auto-TP53 antibodies are detected in certain autoimmune disorders including SSc [11]. TP53 protein acts as a transcription factor, which regulates the expression of genes involved in cell cycle progression, cell growth, and apoptosis. It is encoded by the TP53 gene (locus 17p13.1). The most common studied SNP (rs1042522) is located in codon 72 (exon 4) of the TP53 gene and is associated with the presence of nucleotide with G or C (CGC to CCC). This leads to a replacement of amino acid Arg (R) with Pro (P) in protein structure [12]. The allele encoding Arg ( $\mathrm{R}$ allele-wild type allele) was shown to induce apoptosis more effectively than the P allele [13]. Increased expression of TP53 is consistent with a higher level of apoptosis [14].

NOTCH3 and TP53 signaling pathways are important in cell fate $[15,16]$. The combination of common SNPs might influence both the susceptibility to the disease and specific features of the SSc phenotype [17].

The aim of our study was to evaluate possible associations of NOTCH3 and TP53 SNPs with levels of anti-TP53 antibody, clinical subsets of SSc, clinical profile of SSc patients, particular lung involvement, and disease activity.

\section{Material and Methods}

2.1. Patients and Samples. The study comprised 124 consecutive adult SSc patients and 100 healthy blood donors. The inclusion and exclusion criteria for SSc patients and healthy blood donors are shown in Table 1 . The patients were hospitalized in the Department of Dermatology, Venerology and Pediatric Dermatology of the Medical University of Lublin between June 2017 and March 2019. All patients fulfilled the American Rheumatism Association diagnostic criteria $[18,19]$. Ethical approval was obtained from the Bioethics Committee of Medical University of Lublin [KE0254/145/2017] and each patient signed an informed consent form according to the Helsinki Declaration.

The study population was divided into two groups-lcSSc $(n=101)$ and dcSSc $(n=23)$-according to the classification criteria for systemic sclerosis subsets $[5,20]$. Furthermore, based on the disease duration from the first non-Raynaud symptom, SSc patients were divided into an early ( $<5$ years for $1 \mathrm{cSSc}$ and $<3$ years for $\mathrm{dcSSc}$ ) and late ( $>5$ years for lcSSc and $>3$ years for dcSSc) stage of SSc ( $n=41$ and $n=83$, respectively) [21]. Routine laboratory and imaging diagnostic tests were performed to determine the disease activity and lung involvement. Levels of C-reactive protein (CRP), erythrocyte sedimentation rate (ESR), and complement components 3 and 4 (C3 and C4) were analyzed. Lung involvement was evaluated by high-resolution computed tomography (HRCT), spirometry, and diffusing lung capacity for carbon monoxide (DLCO). To determine disease activity, we used a 10-point activity index for SSc developed by the European Scleroderma Study Group (EScSG). Results of $\geq 3$ points were indicative for active disease [22]. All patients were tested for circulating autoantibodies, such as antinuclear antibodies (ANA), anticentromere antibodies (ACA), anti-topoisomerase I (antiScl-70), and anti-polymerase RNAIII antibodies, following standard methods. SSc patients' characteristics are shown in Table 2.

Control peripheral blood samples were collected from 100 adult, healthy blood donors (50 males and 50 females) attending the Regional Blood Donation and Blood Treatment Center in Kielce, Poland.

2.2. DNA Isolation. DNA isolation from peripheral blood was performed using a commercial kit (Qiagen, Germany) according to the manufacturer's procedure. The concentration and quality of DNA were checked using NanoDrop device (Thermo Fisher Scientific, USA). A total of 124 SSc patients and 100 healthy blood donors were genotyped.

2.3. NOTCH3 and TP53 Genotyping. Two polymorphisms were assessed by PCR-restriction fragment length polymorphism (RFLP). Each PCR mix $(25 \mu \mathrm{l})$ contained $150 \mathrm{ng}$ genomic DNA, PCR buffer (Clontech Laboratories, USA), dNTPs mix $(0.25 \mathrm{mM})$, HD polymerase (Clontech Laboratories, USA), and primers (10 $\mu \mathrm{M}$ of each). The mix was heated to $94^{\circ} \mathrm{C}$ for $5 \mathrm{~min}$ and underwent 35 cycles of amplification for $\mathrm{NOTCH} 3$ and TP53: denaturation $98^{\circ} \mathrm{C}$ for $10 \mathrm{~s}$ and $94^{\circ} \mathrm{C}$ for $15 \mathrm{~s}$, annealing $64^{\circ} \mathrm{C}$ for $10 \mathrm{~s}$ and $55^{\circ} \mathrm{C}$ for $10 \mathrm{~s}$, and elongation $72^{\circ} \mathrm{C}$ for $20 \mathrm{~s}$ and $72^{\circ} \mathrm{C}$ for $30 \mathrm{~s}$, respectively. The final elongation took $5 \mathrm{~min}$ at $72^{\circ} \mathrm{C}$. The PCR reaction was performed using an Applied Biosystems 9700 Thermal Cycler. The following primers were used in PCR reaction:

(i) NOTCH3forward $5^{\prime}$-CTT ACC TGG CAG TCC CAG G-3'

(ii) NOTCH3reverse $5^{\prime}$-AGT GGC AGT GGC TGG GCT AG-3'

or

(i) TP53 forward 5'-TTG CCG TCC CAA GCA ATG GAT GA-3'

(ii) TP53 reverse $5^{\prime}$-TCT GGG AAG GGA CAG AAG ATG AC-3'

The PCR products of NOTCH3 or TP53 were digested for 16 hours at $37^{\circ} \mathrm{C}$ with MwoI (HpyF10VI) or BstUI restriction enzymes (Thermo Fisher Scientific, USA), respectively. RFLP products were analyzed on 3\% agarose gel, 
TABLE 1: Inclusion and exclusion criteria of SSc patients and healthy blood donors.

\begin{tabular}{|c|c|c|}
\hline & Inclusion criteria & Exclusion criteria \\
\hline $\begin{array}{l}\text { SSc } \\
\text { patients }\end{array}$ & $\begin{array}{c}\text { (i) Adult patients } \\
\text { (ii) Signed informed consent } \\
\text { (iii) Diagnosed with SSc and treated in the Chair and } \\
\text { Department of Dermatology, Venerology and Pediatric } \\
\text { Dermatology, Medical University of Lublin, Poland } \\
\text { (iv) Unrelated individuals } \\
\text { (v) Caucasian race from South-Western Poland }\end{array}$ & $\begin{array}{l}\text { (i) Other connective tissue diseases, SSc-like illnesses related } \\
\text { to exposures or ingestions } \\
\text { (ii) Non-Caucasian in race }\end{array}$ \\
\hline $\begin{array}{l}\text { Control } \\
\text { group }\end{array}$ & $\begin{array}{l}\text { (i) Adult, healthy blood donors } \\
\text { (ii) Signed informed consent } \\
\text { (iii) Agreed to have blood donated and stored for research in } \\
\text { Regional Blood Donation and Blood Treatment Center in } \\
\text { Kielce, Poland } \\
\text { (iv) Caucasian race from South-Western Poland }\end{array}$ & $\begin{array}{l}\text { (i) Known to be infected with HIV, syphilis, tuberculosis, } \\
\text { hepatitis B or hepatitis C } \\
\text { (ii) A condition in which repeated blood draws or injections } \\
\text { pose more than minimal risk for the subject such as } \\
\text { hemophilia, other severe coagulation disorders, or } \\
\text { significantly impaired venous access } \\
\text { (iii) A condition that requires active medical intervention or } \\
\text { monitoring to avert serious danger to the participant's health } \\
\text { or well-being } \\
\text { (iv) Non-Caucasian in race }\end{array}$ \\
\hline
\end{tabular}

TABLE 2: Clinical and laboratory parameters of SSc patients according to subtypes and genotypes.

\begin{tabular}{|c|c|c|c|c|c|c|c|c|c|c|}
\hline \multirow[b]{2}{*}{ SSc features } & \multirow{2}{*}{$\begin{array}{c}\text { All SSc } \\
\text { patients } \\
n=124\end{array}$} & \multicolumn{3}{|c|}{ SSc subtypes } & \multicolumn{3}{|c|}{ NOTCH3 } & \multicolumn{3}{|c|}{ TP53 } \\
\hline & & $\begin{array}{c}1 \mathrm{lcSSc} \\
n=101\end{array}$ & $\begin{array}{l}\mathrm{dcSSc} \\
n=23\end{array}$ & $\begin{array}{c}p \\
\text { value }\end{array}$ & $\begin{array}{c}\text { TT } \\
n=97\end{array}$ & $\begin{array}{c}\mathrm{CT}+\mathrm{CC} \\
n=27 \\
\end{array}$ & $\begin{array}{c}p \\
\text { value }\end{array}$ & $\begin{array}{c}\mathrm{RR} \\
n=72\end{array}$ & $\begin{array}{c}\mathrm{PR}+\mathrm{PP} \\
n=52\end{array}$ & $\begin{array}{c}p \\
\text { value }\end{array}$ \\
\hline Age in years, $M$ & 56.7 & 58.96 & 48.26 & $<0.001$ & 56.62 & 58.22 & 0.52 & 56.80 & 56.7 & 0.96 \\
\hline Active disease, $n(\%)$ & $91(73.4)$ & $73(72.2)$ & $18(78.3)$ & 0.56 & $74(76.3)$ & $10(37)$ & $<0.001$ & $18(25)$ & $15(28.8)$ & 0.63 \\
\hline Inactive disease, $n(\%)$ & $33(26.6)$ & $28(27.8)$ & $5(21.7)$ & & $23(23.7)$ & $17(63)$ & & $54(75)$ & $37(71.2)$ & \\
\hline $\begin{array}{l}\text { Disease duration in years, } \\
\mathrm{M}\end{array}$ & 8.75 & 11.12 & 11.98 & 0.59 & 11.06 & 12.05 & 0.51 & 11.42 & 10.81 & 0.63 \\
\hline Early lcSSc, $M$ & - & 4.12 & - & - & 3.70 & 3.57 & 0.77 & 3.25 & 4.11 & 0.022 \\
\hline Late lcSSc, $M$ & - & 13 & - & - & 13.78 & 14.10 & 0.84 & 14.92 & 12.18 & 0.056 \\
\hline Early dcSSc, $M$ & - & - & 2.50 & - & 2.25 & - & - & 2.5 & - & - \\
\hline Late dcSSc, $M$ & - & - & 14.55 & - & 14.87 & 13.0 & 0.51 & 14.64 & 14.25 & 0.88 \\
\hline \multicolumn{11}{|l|}{$\begin{array}{l}\text { Antinuclear antibodies, } \\
n(\%)\end{array}$} \\
\hline $\begin{array}{l}\text { Anti-Scl-70 (anti- } \\
\text { topoisomerase I) } \\
\text { positivity }\end{array}$ & $66(53.2)$ & $43(42.5)$ & $23(100)$ & $<0.001$ & $48(49.5)$ & $18(66.7)$ & 0.11 & $42(58.4)$ & $24(46.1)$ & 0.17 \\
\hline ACA positivity & $49(39.6)$ & $49(48.5)$ & 0 & $<0.001$ & $43(44.3)$ & $6(22.3)$ & 0.003 & $25(34.7)$ & $24(46.1)$ & 0.19 \\
\hline $\begin{array}{l}\text { Anti-RNA polymerase } \\
\text { III positivity }\end{array}$ & $2(1.6)$ & $2(2)$ & 0 & $*$ & $2(2)$ & 0 & $*$ & 0 & $2(3.8)$ & $*$ \\
\hline $\begin{array}{l}\text { Other (anti-fibrillarin, } \\
\text { ANA-speckled pattern) }\end{array}$ & $7(5.6)$ & $7(7)$ & 0 & $*$ & $4(4.1)$ & $3(11)$ & $*$ & $5(6.9)$ & $2(3.8)$ & $*$ \\
\hline $\begin{array}{l}\text { Complement protein C3 } \\
\text { level }(\mathrm{g} / \mathrm{L}), M\end{array}$ & 1.23 & 1.14 & 1.08 & 0.38 & 1.11 & 1.17 & 0.34 & 1.09 & 1.15 & 0.20 \\
\hline $\begin{array}{l}\text { Complement protein } \mathrm{C} 4 \\
\text { level }(\mathrm{g} / \mathrm{L}), M\end{array}$ & 0.24 & 0.23 & 0.23 & 0.87 & 0.24 & 0.22 & 0.55 & 0.22 & 0.25 & 0.24 \\
\hline $\begin{array}{l}\text { C-reactive protein level } \\
(\mathrm{mg} / \mathrm{L}), M\end{array}$ & 7.75 & 7.67 & 7.93 & 0.93 & 6.93 & 10.54 & 0.21 & 6.45 & 8.58 & 0.34 \\
\hline $\begin{array}{l}\text { Erythrocyte } \\
\text { sedimentation rate } \\
(\mathrm{mm} / \mathrm{h}), M\end{array}$ & 24.0 & 22.55 & 28.30 & 0.15 & 22.49 & 27.66 & 0.17 & 22.21 & 25.36 & 0.33 \\
\hline $\begin{array}{l}\text { Interstitial lung disease, } \\
n(\%)\end{array}$ & $98(79)$ & $79(78.2)$ & $19(82.6)$ & * & $76(78.4)$ & $22(81.5)$ & 0.73 & $55(76.4)$ & $43(82.7)$ & 0.39 \\
\hline $\begin{array}{l}\text { Total lung capacity } \\
\text { (TLC)—\% of norm }\end{array}$ & 97 (15.5) & 89.2 & 84.35 & 0.31 & 87.47 & 90.26 & 0.40 & 88.94 & 86.62 & 0.55 \\
\hline TLC $\geq 80 \%$ & 89 & 76 & 13 & 0.07 & 69 & 20 & 0.76 & 51 & 38 & 0.77 \\
\hline TLC $<80 \%$ & 35 & 25 & 10 & & 28 & 7 & & 21 & 14 & \\
\hline
\end{tabular}

M: mean. ${ }^{*}$ Too small group for analysis. 
stained with SimplySafe (Eurx, Poland), and visualized in G: Box (Syngene, Great Britain). The $\mathrm{C}$ or T alleles of the $\mathrm{NOTCH} 3$ gene were identified by the presence of $158 \mathrm{bp}$ (CC genotype) or $203 \mathrm{bp}$ (TT genotypes) fragments, respectively. Heterozygous CT genotype showed the presence of two bands-158 bp and $203 \mathrm{bp}$ (Figure 1(a)). The TP53 alleles were identified by the presence of two $113 \mathrm{bp}$ and $86 \mathrm{bp}$ fragments (for the presence of $\mathrm{R}$ allele) or one fragment of $199 \mathrm{bp}$ (for the presence of $\mathrm{P}$ allele) (Figure 1(b)). An independent PCR analysis was carried out for each sample.

The results of NOTCH3 and TP53 polymorphisms analysis obtained by PCR-RFLP were confirmed by the use of automated Sanger DNA sequencing of PCR-amplicons. The same primers for PCR-RFLP were used. Each PCR mixture $(25 \mu \mathrm{l})$ contained $50 \mathrm{ng}$ genomic DNA, PCR buffer (Clontech), dNTPs mixture $(0.25 \mathrm{mM})$, HD polymerase $(0,31 \mathrm{U})$ (Clontech), and primers $(10 \mu \mathrm{M}$ of each). The PCR conditions were the same as described above. Sequencing PCR was performed with the use of BigDye Terminator v3.1 Cycle Sequencing Kit (Applied Biosystems) in a thermal cycler (as previously mentioned). The sequencing PCR product was purified by the use of an exterminator kit (A\&A Biotechnology). The sequencing run module was StdSeq50_POP7 in genetic analyzer 3130 (Applied Biosystems). The results were analyzed by the use of Applied Biosystems software (Figure 2).

2.4. Anti-TP53 Antibodies Analysis. Serum-circulating TP53 antibodies (p53 antibodies) were analyzed in all SSc groups by ELISA using a commercially available kit (Wuhan Fine Biological Technology, China) according to the manufacturer's instructions. Patients treated with steroids and/or immunosuppressive medications discontinued therapy for at least one month before sample collection. No other drugs were discontinued, on the basis of their limited impact on immune system activity.

2.5. Statistical Analysis. An independent $t$-test was used for the analysis of continuous variables and the Chi-square test-for categorical variables. The association of studied polymorphisms with clinical or laboratory values/factors was evaluated using the Chi-square test or Fischer's exact test (when the expected value was $<5$ ). The quantitative data was shown as frequency or percentage. Deviation of genotype frequencies in controls and cases from HardyWeinberg equilibrium (HWE) was assessed by the Chisquare test with one degree of freedom $(\mathrm{d} f)$ using Michael $\mathrm{H}$. Court's (2005-2008) calculator [23]. For a 95\% confidence interval (CI), we assumed $p=0.05$ and $\chi^{2}=3.84$; therefore, if the $\chi^{2} \leq 3.84$ and the corresponding $p>0.05$, then the population is in HWE. The statistical power of the study was calculated according to Bacchetti and Leung 2008 [24]. We assumed a $5 \%$ error of inference and the related level of significance $p<0.05$ pointing to the existence of statistically significant differences. Statistical analyses were performed using the Statistica ver. 12.5 (StatSoft) software.

\section{Results}

124 SSc patients with a median age of 56.7 years (range $32-79)$ and 100 healthy blood donors with a median age of 34.4 years (range 18-61 years) were included in the study. Genotyping was successful in all individuals. The HWE test showed that genotypic frequencies of NOTCH3 gene for SSc patients diverged significantly from the equilibrium, which indicates a possible association of these genotypes with the disease (Table 3). The frequencies of TP53 genotypes were in HWE.

The differences between allele frequencies of NOTCH3 and TP53 genes in control and study populations were statistically insignificant (Table 4). The CT and CC genotypes of NOTCH3 gene were analyzed as one group, because the frequency of CC homozygotes was very low in SSc patient and control groups-4\% (5 cases) and 2\% (2 cases), respectively. An association between CT + CC genotypes and SSc susceptibility was observed $-\mathrm{OR}$ (odds ratio) $=1.85, p=$ 0.04 (Table 4). The statistical power of this study was 0.37 . Additionally, CT + CC genotypes were associated with a 3fold higher risk of dcSSc. The statistical power of this association was 0.66 . The presence of P allele of TP53 gene was low too, and PR and PP genotypes were analyzed in the clustered group. The association between TP53 (PR + RR) genotypes and susceptibility of dcSSc was statistically significant $(p=0.034)$ with statistical power being equal to 0.69. Furthermore, the combination effect of both studied SNPs did not show the influence on SSc susceptibility (Table 5).

Next, we analyzed the potential relationship between clinical values and laboratory results with SSc susceptibility. We observed the association of CT + CC genotypes and active form of SSc (OR $=5.46$ (95\% CI 2.20-13.59), $p<0.001)$ (Table 2) and a higher risk of dcSSc (OR $=3.43$ (95\% CI 0.95-12.37), $p=0.04$ ) (Table 4). While analyzing TP53 genotypes, we found a relationship between $\mathrm{PR}+\mathrm{PP}$ genotypes and a higher risk of dcSSc $(\mathrm{OR}=3.30(1.04-10.41), p=0.034)$ (Table 4).

In the case of serum level of anti-TP53 antibodies, we did not observe statistically significant differences between TT and $\mathrm{CT}+\mathrm{CC}$ genotypes of $\mathrm{NOTCH} 3$ gene $(6.41 \mathrm{ng} / \mathrm{mL}$ versus $5.90 \mathrm{ng} / \mathrm{mL}(p=0.57))$ as well as TP53 genotypes (RR versus $\mathrm{PR}+\mathrm{PP})(5.54 \mathrm{ng} / \mathrm{mL}$ versus $6.67 \mathrm{ng} / \mathrm{mL}(p=0.14))$.

\section{Discussion}

In this study, we have explored the association of NOTCH3 and TP53 polymorphisms, as well as the level of anti-TP53 antibodies with SSc susceptibility and pattern in the Caucasian population. To our knowledge, this is the first study to elicit the significance of SNPs in SSc. Our findings suggest that the genotypes of NOTCH3 and TP53 genes are associated with higher susceptibility of dcSSc.

DcSSc affected various skin areas and visceral organs including lungs [25]. The development of dcSSc may be induced by cell cycle arrest, activation of DNA repair mechanisms, and inactivation of the apoptosis pathway [26]. It is known that the inhibition of apoptosis is a key 


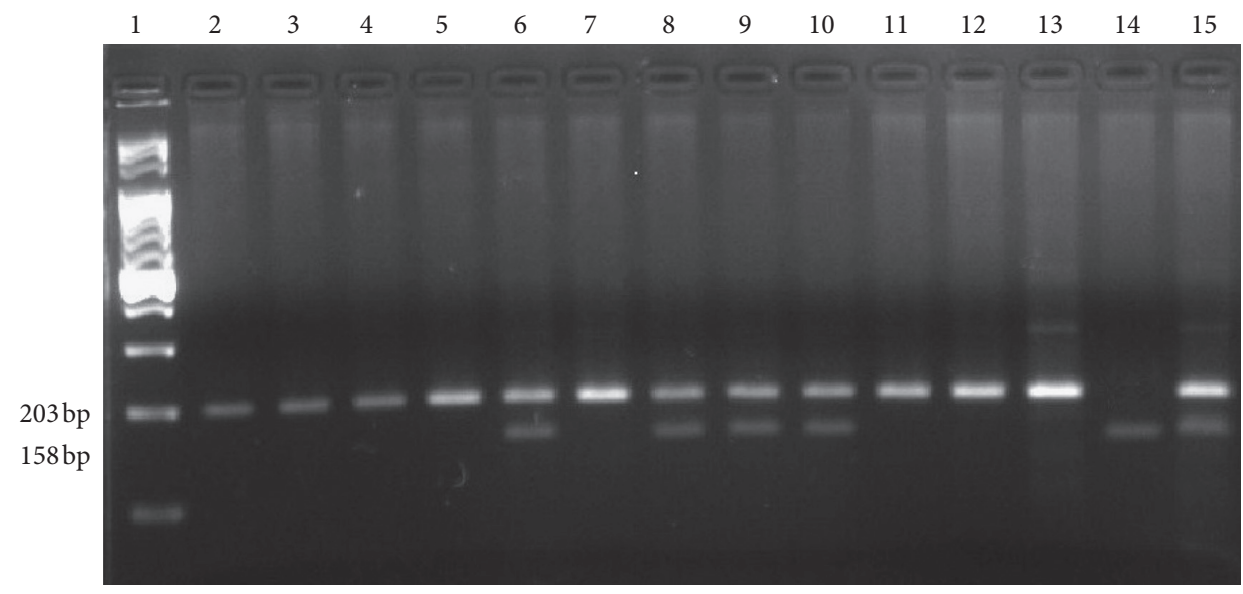

(a)

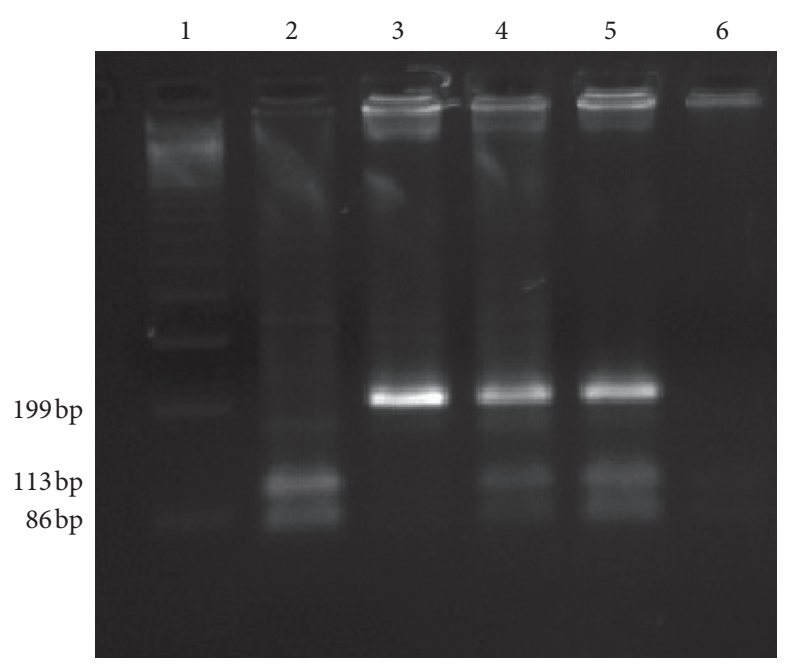

(b)

FIGURE 1: PCR-RFLP of studied polymorphisms. (a) T6746C NOTCH3 polymorphism. Lane 1: Ladder (100 bp); Lanes 2-5, 7, and 11-13: TT genotypes; Lanes 6, 8-10, and 15: CT heterozygotes; Lane 14: CC homozygote. (b) P72R TP53 polymorphism. Lane 1: Ladder (100 bp); Lanes 2 and 6: RR genotypes; Lane 3: PP genotype; Lanes 4 and 5: PR heterozygotes.

mechanism of fibrosis [27]. In the present study, the relationship between PR and PP genotypes of the TP53 gene and dcSSc susceptibility was observed. TP53 P72R polymorphism affects the function and expression of TP53 protein. The P72R polymorphism is present in the segment encoding the transactivation domain and may increase the expression of this gene and the levels of anti-TP53 antibodies [28].

Several studies were focused on the role of serum antiTP53 antibodies in the development of malignant disorders $[29,30]$. Patients with various types of cancers and TP53 mutations show a specific autoimmune response to TP53 protein [31]. However, some studies suggested that serum anti-TP53 antibodies might be detected in certain autoimmune disorders [32]. For example, patients with systemic lupus erythematosus secrete an antibody to the C-terminal domain of TP53, which can inhibit the function of this protein [33]. Mimura and coworkers in the study of 25 patients with SSc and 20 healthy controls found no statistical difference in the level of these antibodies between both study groups [34]. Moreover, Mahmoudi showed no significant alteration in mRNA expression levels of the TP53 gene in fibroblasts from SSc patients compared with healthy controls [35]. This is why we did not analyze serum anti-TP53 antibody in the control population, since we focused on the association of these antibodies with SSc susceptibility and pattern: this included the levels of serum antinuclear antibodies. In our study, we did not observe a relationship between anti-TP53 antibodies level and SSc susceptibility, activity, nor interstitial lung disease.

The NOTCH pathway is involved in the pathogenesis of diseases associated with abnormal fibrosis, including the development of idiopathic pulmonary fibrosis and SSc [36-38]. Activation of the NOTCH pathway in the endothelium leads to morphological, phenotypic, and functional changes in epithelial cells [39]. Several papers suggested that an overexpression of NOTCH signaling may have fibrogenic effects in a wide spectrum of diseases, including SSc [40]. Dees et al. found the activation of the NOTCH pathway in SSc with a prominent expression of ligand Jag-1 in infiltrating T-cells [37]. In human adults, NOTCH3 is expressed 


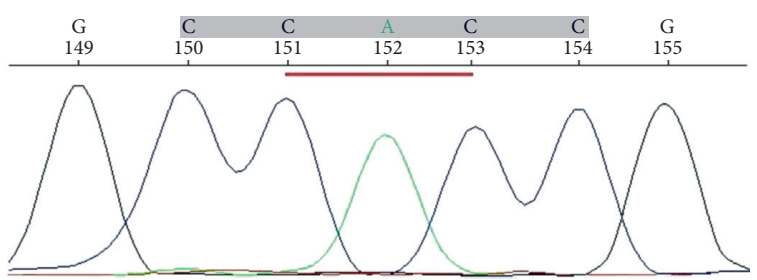

(a)
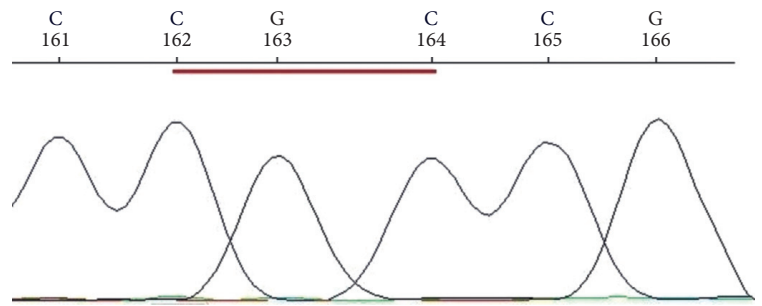

(c)

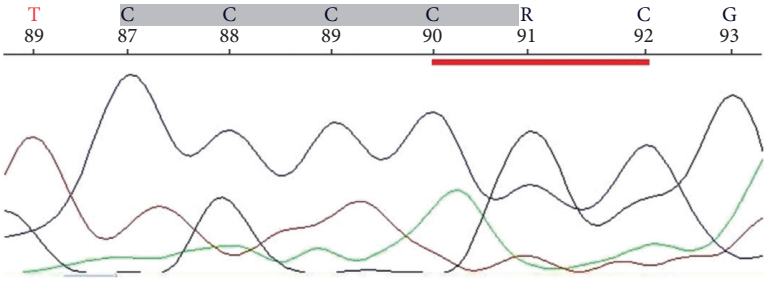

(e)

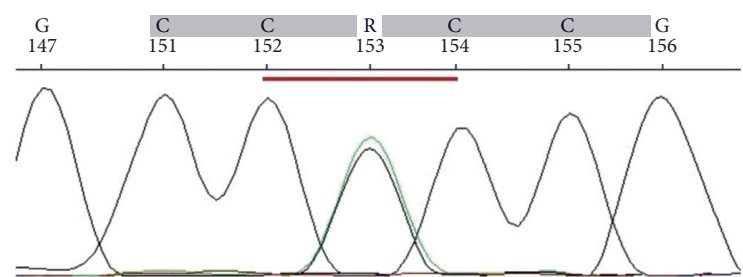

(b)

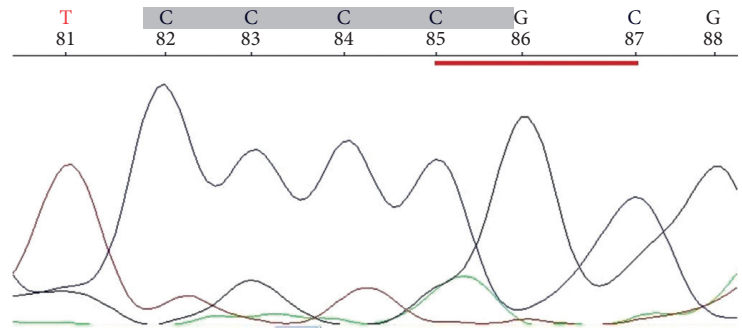

(d)

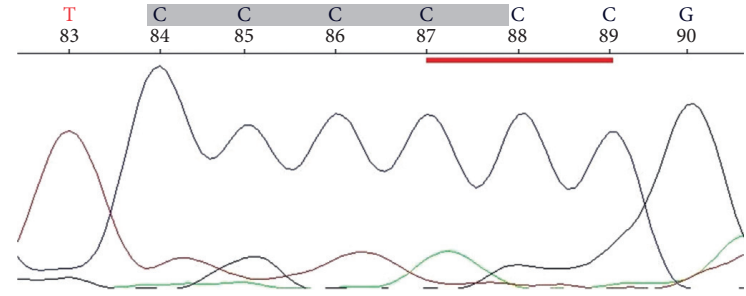

(f)

Figure 2: Electropherograms obtained by automated Sanger DNA sequencing. (a-c) Sequencing of the NOTCH3 gene, the sequences referred to R strand. (a) AA homozygote (on F strand-TT, T alleles), (b) heterozygote (T and C alleles), and (c) GG homozygote (on F strand-CC, C alleles). (d-f) Sequencing of the TP53 gene. (d) GG homozygote (R alleles), (e) heterozygote (P and R alleles), and (f) CC homozygote (P alleles).

TABLE 3: Hardy-Weinberg equilibrium for NOTCH3 and TP53 polymorphisms in the case and control groups according to expected E and observed $\mathrm{O}$ values.

\begin{tabular}{|c|c|c|c|c|c|c|c|c|c|c|}
\hline & TT & CT & $\mathrm{CC}$ & Total & HWE $p$ value and $\chi^{2 *}$ & $\mathrm{RR}$ & $\mathrm{PR}$ & $\mathrm{PP}$ & Total & HWE $p$ value and $\chi^{2 *}$ \\
\hline Control & & & & $\mathrm{NOTCH} 3$ & \multirow{3}{*}{$p=0.53, \chi^{2}=0.38$} & & & & TP53 & \multirow{3}{*}{$p=0.63, \chi^{2}=0.22$} \\
\hline $\mathrm{E}$ & 67 & 30 & 3 & 100 & & 59 & 36 & 5 & 100 & \\
\hline $\mathrm{O}$ & 66 & 32 & 2 & 100 & & 59 & 35 & 6 & 100 & \\
\hline Case & & & & & \multirow[b]{2}{*}{$p=0.03, \chi^{2}=4.63$} & & & & & \\
\hline $\begin{array}{l}\mathrm{E} \\
\mathrm{O}\end{array}$ & $\begin{array}{l}94 \\
97\end{array}$ & $\begin{array}{l}28 \\
22\end{array}$ & $\begin{array}{l}2 \\
5\end{array}$ & $\begin{array}{l}124 \\
124\end{array}$ & & $\begin{array}{l}72 \\
73\end{array}$ & $\begin{array}{l}44 \\
47\end{array}$ & $\begin{array}{l}7 \\
5\end{array}$ & $\begin{array}{l}124 \\
124\end{array}$ & $p=0.60, \chi^{2}=0.43$ \\
\hline
\end{tabular}

*If $\chi^{2} \leq 3.84$ and the corresponding $p \geq 0.05$, then the population is in HWE.

only in arterial smooth muscle cells (SMCs), and its product participates in artery maturation and specification and responses to vascular injury, regulating vascular SMCs growth and apoptosis [41]. Vascular damage is thought to be involved in SSc development [42]. Early stages of SSc are associated with reduced capillary density [43]. A possible role of $\mathrm{NOTCH} 3$ in myofibroblast differentiation was postulated in an animal model with NOTCH3 synthesis inhibition [44]. In our study, we found a relationship between $\mathrm{CT}+\mathrm{CC}$ genotypes with the susceptibility to various forms of SSc. These genotypes were not in HWE, which suggests their possible association with disease development.

It is known that a cross-talk exists between the NOTCH pathway and TP53 protein function. Giovannini and coworkers found, in an animal model, that activation of the Notch3 receptor might suppress the expression of p53 due to posttranscriptional mechanism [45]. However, in our study, we did not find any relationship between the combination effect of NOTCH3, TP53 polymorphisms, and SSc risk. It is possible that these SNPs exert only a minor effect, and they are linked to other alleles.

A limitation of our study is the relatively small sample size (of lcSSc and dcSSc patients) which in part is due to the low incidence of the disease. This may bias the obtained results, which thus should be considered as preliminary to further testing. Departure from HWE, like in the case of NOTCH3 genotype, can be indicative of potential genotyping errors, population stratification, or association to the 
TABLE 4: The comparison of NOTCH3 and TP53 allele frequencies among SSc patients and controls. The impact of studied polymorphisms on the risk of SSc.

\begin{tabular}{|c|c|c|c|c|c|}
\hline \multirow{2}{*}{$\frac{\text { Alleles }}{\text { NOTCH3 }}$} & SSc cases, $n=248(\%)$ & Controls, $n=200(\%)$ & \multicolumn{3}{|c|}{$p$ values } \\
\hline & & & & & \\
\hline $\mathrm{T}$ & $216(87 \%)$ & $164(82 \%)$ & & 0.13 & \\
\hline $\mathrm{C}$ & $32(13 \%)$ & $36(18 \%)$ & & & \\
\hline Total: & $248(100 \%)$ & $200(100 \%)$ & & - & \\
\hline \multicolumn{6}{|l|}{ TP53 } \\
\hline $\mathrm{R}$ & $191(77 \%)$ & $153(76.5 \%)$ & 0.88 & & \\
\hline $\mathrm{P}$ & $57(23 \%)$ & $47(23.5 \%)$ & & & \\
\hline Total: & $248(100 \%)$ & $200(100 \%)$ & & - & \\
\hline Genotypes & SSc patients $n=124(\%)$ & Controls $n=100(\%)$ & OR & $95 \% \mathrm{CI}$ & $p$ value \\
\hline \multicolumn{6}{|l|}{$\mathrm{NOTCH3}$} \\
\hline $\mathrm{TT}$ & $97(78 \%)$ & $66(66 \%)$ & Reference & - & - \\
\hline \multirow[t]{2}{*}{$\mathrm{CT}+\mathrm{CC}$} & $27(22 \%)$ & $34(34 \%)$ & 1.85 & $1.02-3.35$ & 0.04 \\
\hline & $\operatorname{lcSSc} n=101(\%)$ & Controls $n=100(\%)$ & & & \\
\hline $\mathrm{TT}$ & $77(76 \%)$ & $66(66 \%)$ & Reference & - & - \\
\hline \multirow[t]{2}{*}{$\mathrm{CT}+\mathrm{CC}$} & $24(24 \%)$ & $34(34 \%)$ & 1.65 & $0.89-3.06$ & 0.10 \\
\hline & $\operatorname{dcSSC} n=23(\%)$ & Controls $n=100(\%)$ & & & \\
\hline $\mathrm{TT}$ & $20(87 \%)$ & $66(66 \%)$ & Reference & - & - \\
\hline $\mathrm{CT}+\mathrm{CC}$ & $3(13 \%)$ & $34(34 \%)$ & 3.43 & $0.95-12.37$ & 0.04 \\
\hline \multicolumn{6}{|l|}{ TP53 } \\
\hline $\mathrm{RR}$ & $72(58 \%)$ & $59(59 \%)$ & Reference & - & - \\
\hline \multirow[t]{2}{*}{$P R+P P$} & $52(42 \%)$ & $41(41 \%)$ & 0.96 & $0.56-1.64$ & 0.88 \\
\hline & lcSSc $n=101(\%)$ & Controls $n=100(\%)$ & & & \\
\hline $\mathrm{RR}$ & $53(52 \%)$ & $59(59 \%)$ & Reference & - & - \\
\hline \multirow[t]{2}{*}{$P R+P P$} & $48(48 \%)$ & $41(41 \%)$ & 0.76 & $0.43-1.34$ & 0.35 \\
\hline & $\operatorname{dcSSC} n=23(\%)$ & Controls $n=100(\%)$ & & & \\
\hline $\mathrm{RR}$ & 19 & $59(59 \%)$ & Reference & - & - \\
\hline $\mathrm{PR}+\mathrm{PP}$ & 4 & $41(41 \%)$ & 3.30 & $1.04-10.41$ & 0.034 \\
\hline
\end{tabular}

TABLE 5: Combination effect of NOTCH3 and TP53 polymorphisms on the risk of SSc.

\begin{tabular}{lccccc}
\hline NOTCH3 & TP53 & SSc patients $n$ & Controls $n$ & OR & $95 \%$ CI \\
\hline TT & RR & 60 & 16 & Reference & - \\
CT + CC & PR + RR & 15 & 4 & 1.0 & $0.29-3.43$ \\
\hline
\end{tabular}

trait [46-48]. In our study, the results obtained by the PCR-RFLP method were confirmed by automated Sanger sequencing, so we could exclude the genotyping errors. The population included in the study was ethnically homogeneous. Further analysis on a larger cohort can help to better understand the significance of NOTCH3 and TP53 polymorphisms in the pathobiology of SSc, including dcSSc.

\section{Conclusions}

In summary, the present study provides the first evidence that the $\mathrm{CT}+\mathrm{CC}$ genotypes of NOTCH3 gene and PR + RR genotypes of the TP53 gene increased the risk of dcSSc development. Moreover, genotypes of CT + CC were associated with the active form of SSc suggesting the role of the $\mathrm{NOTCH}$ pathway in the pathogenesis of this disease.

\section{Data Availability}

The clinical data used to support the findings of this study are available from the corresponding author upon request.

\section{Conflicts of Interest}

The authors declare that they have no conflicts of interest.

\section{Authors' Contributions}

SZ and DK planned the study. MK and MMJ performed routine laboratory and imaging diagnostic tests. SZ and MWL performed the molecular analysis of NOTCH3 and TP53 polymorphisms. MK and MMJ performed the analysis of TP-53 antibodies. AAF, IW, and DK supervised the work. WS processed the experimental data and performed the statistical analysis. SZ and WS designed the figures. SZ and MMJ wrote the manuscript with support from AAF, DK, and IW. All authors discussed the results and commented on the manuscript.

\section{Acknowledgments}

The authors are grateful to the patients who participated in this study. The authors would like to thank Iwona KorszenPilecka and Sylwia Popek-Marciniec for assistance with 
molecular analyzes. Special thanks are due to Christiana Lucas and Georgia Lucas for proofreading and editing assistance, as well as substantive verification. This project was supported by the Medical University of Lublin, Poland (Grants MNmb 232 and DS 167).

\section{References}

[1] S. Barsotti, C. Bruni, M. Orlandi et al., "One year in review 2017: systemic sclerosis," Clinical and Experimental Rheumatology, vol. 35, no. 1, pp. 3-20, 2017.

[2] R. Lafyatis, "Transforming growth factor $\beta$-at the centre of systemic sclerosis," Nature Reviews Rheumatology, vol. 10, no. 12, pp. 706-719, 2014.

[3] L. Chung, J. Lin, D. E. Furst, and D. Fiorentino, "Systemic and localized scleroderma," Clinics in Dermatology, vol. 24, no. 5, pp. 374-392, 2006.

[4] S. Harrach, V. Barz, T. Pap et al., "Notch signaling activity determines uptake and biological effect of imatinib in systemic sclerosis dermal fibroblasts," Journal of Investigative Dermatology, vol. 139, no. 2, pp. 439-447, 2019.

[5] F. A. Wollheim, "Classification of systemic sclerosis. Visions and reality," Rheumatology, vol. 44, no. 10, pp. 1212-1216, 2005.

[6] A. Gabrielli, E. V. Avvedimento, and T. Krieg, "Scleroderma," New England Journal of Medicine, vol. 360, no. 19, pp. 1989-2003, 2009.

[7] T. Liu, B. Hu, Y. Y. Choi et al., "Notch1 signaling in FIZZ1 induction of myofibroblast differentiation," The American Journal of Pathology, vol. 174, no. 5, pp. 1745-1755, 2009.

[8] A. D. Lowe, N. Y. Elmadhun, T. A. Burgess et al., "Microvascular notch signaling is upregulated in response to vascular endothelial growth factor and chronic myocardial ischemia," Circulation Journal, vol. 78, no. 3, pp. 743-751, 2014.

[9] D. Bellavia, A. F. Campese, E. Alesse et al., "Constitutive activation of NF-kappaB and T-cell leukemia/lymphoma in Notch3 transgenic mice," The EMBO Journal, vol. 19, no. 13, pp. 3337-3348, 2000.

[10] B. D'Souza, L. Meloty-Kapella, and G. Weinmaster, "Canonical and non-canonical Notch ligands," Current Topics in Developmental Biology, vol. 92, pp. 73-129, 2010.

[11] V. Gandhi, "p53 as a predictor for chemotherapy response in CLL cells," Leukemia \& Lymphoma, vol. 48, no. 2, pp. 219-220, 2007.

[12] J. Malcikova, S. Pavlova, K. S. Kozubik, and S. Pospisilova, "Tp53 mutation analysis in clinical practice: lessons from chronic lymphocytic leukemia," Human Mutation, vol. 35, no. 6, pp. 663-671, 2014.

[13] P. Dumont, J. I.-J. Leu, A. C. Della Pietra, D. L. George, and M. Murphy, "The codon 72 polymorphic variants of p53 have markedly different apoptotic potential," Nature Genetics, vol. 33, no. 3, pp. 357-365, 2003.

[14] C. E. Canman and M. B. Kastan, "Role of p53 in apoptosis," Apoptosls-Pharmacological Implications and Therapeutic Opportunities, vol. 41, pp. 429-460, 1997.

[15] F. Kruiswijk, C. F. Labuschagne, and K. H. Vousden, "p53 in survival, death and metabolic health: a lifeguard with a licence to kill," Nature Reviews Molecular Cell Biology, vol. 16, no. 7, pp. 393-405, 2015.

[16] J. T. Park, X. Chen, C. G. Tropè, B. Davidson, I.-M. Shih, and T.-L. Wang, "Notch3 overexpression is related to the recurrence of ovarian cancer and confers resistance to carboplatin," The American Journal of Pathology, vol. 177, no. 3, pp. 1087-1094, 2010.
[17] Q. Yang, M. J. Khoury, J. Friedman, J. Little, and W. D. Flanders, "How many genes underlie the occurrence of common complex diseases in the population?," International Journal of Epidemiology, vol. 34, no. 5, pp. 1129-1137, 2005.

[18] A. T. Masi, G. P. Rodnan, T. A. Medsger et al., "Preliminary criteria for the classification of systemic sclerosis (scleroderma). Subcommittee for scleroderma criteria of the American Rheumatism Association Diagnostic and Therapeutic Criteria Committee," Arthritis and Rheumatism, vol. 23, pp. 581-590, 1980.

[19] F. van den Hoogen, D. Khanna, J. Fransen et al., "2013 classification criteria for systemic sclerosis: an American college of rheumatology/European league against rheumatism collaborative initiative," Annals of the Rheumatic Diseases, vol. 72, no. 11, pp. 1747-1755, 2013.

[20] S. R. Johnson, B. M. Feldman, and G. A. Hawker, "Classification criteria for systemic sclerosis subsets," The Journal of Rheumatology, vol. 34, no. 34, pp. 1855-1863, 2007.

[21] E. C. LeRoy, C. Black, R. Fleischmajer et al., "Scleroderma (systemic sclerosis): classification, subsets and pathogenesis," Journal of Rheumatology, vol. 15, no. 2, pp. 202-205, 1988.

[22] G. Valentini, A. Della Rossa, S. Bombardieri et al., "European multicentre study to define disease activity criteria for systemic sclerosis. II. Identification of disease activity variables and development of preliminary activity indexes," Annals of the Rheumatic Diseases, vol. 60, no. 6, pp. 592-598, 2001.

[23] M. Court, Michael H. Court's (2005-2008) Online Calculator, Tuft University, Medford, MA, USA, 2012, http://www.tufts. edu/ mcourt01/Documents/Courtlab-HWcalculator.xls.

[24] P. Bacchetti and J. M. Leung, "Sample size calculations in clinical research," Anesthesiology, vol. 97, no. 4, pp. 1028-1029, 2002.

[25] V. Cottin and K. K. Brown, "Interstitial lung disease associated with systemic sclerosis (SSc-ILD)," Respiratory Research, vol. 20, no. 1, p. 13, 2019.

[26] J. Collison, "Promoting apoptosis is key to reversing fibrosis," Nature Reviews Rheumatology, vol. 14, no. 2, p. 61, 2018.

[27] S. Chabaud and V. J. Moulin, "Apoptosis modulation as a promising target for treatment of systemic sclerosis," International Journal of Rheumatology, vol. 2011, Article ID 495792, 13 pages, 2011.

[28] S. Antoun, D. Atallah, R. Tahtouh et al., "Different TP53 mutants in p53 overexpressed epithelial ovarian carcinoma can be associated both with altered and unaltered glycolytic and apoptotic profiles," Cancer Cell International, vol. 18, no. 1, p. 14, 2018.

[29] T. Nozoe, E. Nozoe, M. Kono, T. Ohga, and T. Ezaki, "Further evidence to demonstrate the significance of serum appearance of anti-p53 antibody as a marker for progressive potential in invasive ductal carcinoma of the breast," The Journal of Medical Investigation, vol. 64, no. 3.4, pp. 241-244, 2017.

[30] M. Kunizaki, A. Fukuda, K. Wakata et al., "Clinical significance of serum p53 antibody in the early detection and poor prognosis of gastric cancer," Anticancer Research, vol. 37, no. 4, pp. 1979-1984, 2017.

[31] Y. Hoshida, T. Hongyo, J.-X. Xu et al., “TP53 gene mutation, an unfavorable prognostic factor for malignant lymphomas in autoimmune diseases," Oncology, vol. 69, no. 2, pp. 175-183, 2005.

[32] Z. A. Aozasa, D. H. Farag, and S. Eissa, "Tumor suppressor protein p53 and anti-p53 autoantibodies in pediatric rheumatological diseases," Pediatric Allergy and Immunology, vol. 14, no. 3, pp. 229-233, 2003. 
[33] J. Herkel, N. a. Kam, N. Erez et al., "Monoclonal antibody to a DNA-binding domain of p53 mimics charge structure of DNA: anti-idiotypes to the anti-p53 antibody are anti-DNA," European Journal of Immunology, vol. 34, no. 12, pp. 36233632, 2004.

[34] Y. Mimura, N. Yazawa, Y. Tada, H. Ihn, and K. Tamaki, "Antip53 antibodies in patients with systemic sclerosis," International Journal of Dermatology, vol. 46, no. 5, pp. 549-550, 2007.

[35] M. B. Mahmoudi, M. Abed Khojasteh, F. Alsahebfosoul et al., "Expressions of p53 and PUMA in fibroblasts of systemic sclerosis patients are normal at transcription level," Journal of Cosmetic Dermatology, vol. 17, no. 3, pp. 549-554, 2018.

[36] A. Mahmoudi, S. A. Nam, W.-Y. Kim et al., "Notch signaling in the collecting duct regulates renal tubulointerstitial fibrosis induced by unilateral ureteral obstruction in mice," The Korean Journal of Internal Medicine, vol. 33, no. 4, pp. 774782, 2018.

[37] C. Kim, M. Tomcik, P. Zerr et al., "Notch signalling regulates fibroblast activation and collagen release in systemic sclerosis," Annals of the Rheumatic Diseases, vol. 70, no. 7, pp. 1304-1310, 2011

[38] C. Dees, P. Zerr, M. Tomcik et al., "Inhibition of Notch signaling prevents experimental fibrosis and induces regression of established fibrosis," Arthritis \& Rheumatism, vol. 63, no. 5, pp. 1396-1404, 2011.

[39] M. Noseda, G. McLean, K. Niessen et al., "Notch activation results in phenotypic and functional changes consistent with endothelial-to-mesenchymal transformation," Circulation Research, vol. 94, no. 7, pp. 910-917, 2004.

[40] N. Kavian, A. Servettaz, C. Mongaret et al., "Targeting ADAM-17/notch signaling abrogates the development of systemic sclerosis in a murine model," Arthritis \& Rheumatism, vol. 62, no. 11, pp. 3477-3487, 2010.

[41] N. Villa, L. Walker, C. E. Lindsell, J. Gasson, M. L. IruelaArispe, and G. Weinmaster, "Vascular expression of Notch pathway receptors and ligands is restricted to arterial vessels," Mechanisms of Development, vol. 108, no. 1-2, pp. 161-164, 2001.

[42] G. L. Bagnato, W. N. Roberts, A. Fiorenza et al., "Skin fibrosis correlates with circulating thyrotropin levels in systemic sclerosis: translational association with Hashimoto's thyroiditis," Endocrine, vol. 51, no. 2, pp. 291-297, 2016.

[43] V. D. Steen and T. A. Medsger, "Changes in causes of death in systemic sclerosis, 1972-2002," Annals of the Rheumatic Diseases, vol. 66, no. 7, pp. 940-944, 2007.

[44] Y. Chen, S. Zheng, D. Qi et al., "Inhibition of notch signaling by a $\gamma$-secretase inhibitor attenuates hepatic fibrosis in rats," PLoS One, vol. 7, no. 10, Article ID e46512, 2012.

[45] C. Giovannini, L. Gramantieri, P. Chieco et al., "Selective ablation of Notch3 in HCC enhances doxorubicin's death promoting effect by a p53 dependent mechanism," Journal of Hepatology, vol. 50, no. 5, pp. 969-979, 2009.

[46] S. Turner, L. L. Armstrong, Y. Bradford et al., "Quality control procedures for genome-wide association studies," Current Protocols in Human Genetics, vol. 68, no. 1, p. 1, 2011.

[47] J. K. Wittke-Thompson, A. Pluzhnikov, and N. J. Cox, "Rational inferences about departures from hardy-weinberg equilibrium," The American Journal of Human Genetics, vol. 76, no. 6, pp. 967-986, 2005.

[48] S. Zmorzynski, A. Szudy-Szczyrek, S. Popek-Marciniec et al., "ACE insertion/deletion polymorphism (rs4646994) is associated with the increased risk of multiple myeloma," Frontiers in Oncology, vol. 9, p. 44, 2019. 